\title{
Azocasein Substrate for Determination of Proteolytic Activity: Reexamining a Traditional Method Using Bromelain Samples
}

\author{
Diego F. Coêlho, ${ }^{1}$ Thais Peron Saturnino, ${ }^{1}$ Fernanda Freitas Fernandes, ${ }^{1}$ \\ Priscila Gava Mazzola, ${ }^{2}$ Edgar Silveira, ${ }^{3}$ and Elias Basile Tambourgi ${ }^{1}$ \\ ${ }^{1}$ Chemical Engineering School, Campinas State University (UNICAMP), Avenida Albert Einstein 500, 13083-852 Campinas, SP, Brazil \\ ${ }^{2}$ Faculty of Pharmaceutical Sciences, Campinas State University (UNICAMP), Rua Sérgio Buarque de Holanda 250, \\ 13083-859 Campinas, SP, Brazil \\ ${ }^{3}$ Biochemistry and Genetics Institute, Federal University of Uberlândia (UFU), Avenida Getúlio Vargas, 230 Centro, \\ 38700-128 Patos de Minas, MG, Brazil
}

Correspondence should be addressed to Diego F. Coêlho; dfcoelho@feq.unicamp.br

Received 26 November 2015; Accepted 12 January 2016

Academic Editor: Pengjun Shi

Copyright (C) 2016 Diego F. Coêlho et al. This is an open access article distributed under the Creative Commons Attribution License, which permits unrestricted use, distribution, and reproduction in any medium, provided the original work is properly cited.

Given the importance of protease's worldwide market, the determination of optimum conditions and the development of a standard protocol are critical during selection of a reliable method to determine its bioactivity. This paper uses quality control theory to validate a modified version of a method proposed by Charney and Tomarelli in 1947. The results obtained showed that using azocasein substrate bromelain had its optimum at $45^{\circ} \mathrm{C}$ and pH 9 (Glycine- $\mathrm{NaOH} 100 \mathrm{mM}$ ). We also quantified the limit of detection (LoD) and limit of quantification (LoQ) in the above-mentioned optimum $\left(0.072\right.$ and $0.494 \mathrm{mg} \cdot \mathrm{mL}^{-1}$ of azocasein, resp.) and a calibration curve that correlates optical density with the amount of substrate digested. In all analysed samples, we observed a significant decrease in response after storage (around 17\%), which suggests its use must be immediately after preparation. Thus, the protocol presented in this paper offers a significant improvement, given that subjective definitions are commonly used in the literature and this simple mathematical approach makes it clear and concise.

\section{Introduction}

Because proteases represent the largest and most important segment in the industrial enzyme market [1], the consolidation of a reliable method to evaluate its quality is obviously of extreme importance. These enzymes are used in detergents, food processing, and leather industry, as biocatalysts in organic synthesis, and, among many other applications, as therapeutics because their roles are involved in key decisions throughout an organism in several physiological and metabolic processes [2].

The global market for industrial enzymes is expected to reach US $\$ 7.1$ billion by 2018 [3] and is traditionally divided into three segments: food, technical, and feed enzymes. In 2000, technical enzymes used in detergent, leather, textile, and personal care industries accounted for 65\% [4] of the total sales (approximately US $\$ 1.5$ billion [5]), while food enzymes, which include enzymes used in dairy, brewing, wine, and juices, were valued at $25 \%$ and feed enzymes (used in animal feeds) contributed with $10 \%$.

Nearly 70 years ago, Charney and Tomarelli [6] proposed the use of an azoprotein (a protein coupled with diazotized aryl amines) for the determination of proteolytic activity. The digestion of a solution with such proteins releases the chromophoric group, which is soluble in trichloroacetic acid and gives it a red-orange colour.

The method itself relies on the reaction between the substrate and an enzyme under its optimum temperature/pH for a given time. The solution colour intensity, read at $440 \mathrm{~nm}$, is a function of the amount of azoprotein digested, since all proteins remaining precipitate after the addition of trichloroacetic acid.

The method is still one of the most reliable methods to study the proteolytic activity of enzymes $[7,8]$ due its colour 
stability and no need of chromogenic reagents. Besides, the sulphanilamide-azocasein's preparation is no longer necessary, since it is now available widely in the market.

However, the available protocols that describe thoroughly the method still are lacking in presenting the evaluation of its analytical parameters, required for method validation. Thus, this study aims to review and validate the azocasein method to establish its detection and quantification limits, in addition to reagent storage stability and a quantitative definition of enzymatic activity.

\section{Materials and Methods}

2.1. Bromelain Sample and Other Chemicals. Bromelain (catalogue B5144) and azocasein (catalogue A2765) obtained from Sigma-Aldrich (St. Louis, USA) were chosen as standards for these studies, being used to prepare stock solutions at different $\mathrm{pH}$. Unless specified, all other reagents were also obtained from Sigma-Aldrich.

2.2. Substrate Solution. Given the nature of this study, the amount of powdered substrate and buffer used will depend on the concentration and $\mathrm{pH}$ of each experiment. The substrate's $\mathrm{pH}$ and concentration are part of the studied variables and are described in the following methods. All pH buffers were prepared following common protocols described elsewhere [9].

Basically, $4 \mathrm{~mL}$ of ethanol is added to the powdered substrate in a $120 \mathrm{~mL}$ beaker and is stirred using a magnetic stirrer to solubilise all aggregated protein and is then diluted with $96 \mathrm{~mL}$ of appropriated buffer $(100 \mathrm{mM})$.

2.3. Bromelain Stock Solution. Bromelain stock solution was prepared following a modified version of a method described by Hale et al. [10]. The $1 \mathrm{mg} \cdot \mathrm{mL}^{-1}$ enzyme solution was prepared using a $100 \mathrm{mM}$ buffer of different $\mathrm{pH}$ (since it was also under investigation). Concentration was chosen based on its maximum solubility at experimental conditions.

2.4. Enzymatic Assay. The method consists in mixing equal volumes of substrate and enzymatic sample at a given temperature and $\mathrm{pH}$ that corresponds to the optimum conditions of the enzyme under investigation. For practical reasons we chose $125 \mu \mathrm{L}$, as it is small enough to avoid wasting resources and does not compromise the method's precision.

The kinetics of the digestion were studied during 420 minutes using substrate's concentration in a range from 0.1 to $3.0 \%(\mathrm{w} / \mathrm{w})$ in order to determine a suitable time of digestion.

The reaction was terminated adding $750 \mu \mathrm{L}$ of $5 \%$ trichloroacetic acid (TCA) to the enzyme-substrate mixture. The coagulated protein was removed by centrifugation at $2000 \times \mathrm{g}$ for $10 \mathrm{~min}$ at room temperature. The obtained supernatant was then added to a $0.5 \mathrm{~N} \mathrm{NaOH}$ solution using a $1: 1$ $(\mathrm{v} / \mathrm{v})$ ratio and its absorbance was read at $440 \mathrm{~nm}$.

The blank was obtained by mixing the TCA to the substrate prior to the enzyme addition.

2.5. Optimum $\mathrm{pH}$ and Temperature for Bromelain. The optimum $\mathrm{pH}$ and temperature for assaying bromelain's activity were determined by performing a full factorial design of experiments using both variables in two levels and three central points. The $\mathrm{pH}$ ranged from 6 to 8 and temperature from $25^{\circ} \mathrm{C}$ to $45^{\circ} \mathrm{C}$ in the factorial design. Temperature was kept constant during substrate digestion by using a Techne ${ }^{\circledR}$ Dri-Block ${ }^{\circledR}$ heater, model DB-3D.

This design was extended to a central composite design, which had its variable's range adjusted based on the results of the first design. All statistical data was generated and analysed using R [11], coupled with R-Studio [12], and using packages akima [13], DoE.base [14], ggplot2 [15], and RColorBrewer [16].

2.6. Calibration Curve. Using the curves of azocasein digestion obtained previously (as described in the topic Enzymatic Assay), a correlation between the colour intensity and the substrate concentration was created.

The principle is simple: if the enzymes digest the substrate for enough time, we would achieve the solution maximum colour intensity, since all chromophoric groups had their bonds to the protein broken and thus are soluble in TCA. This satisfies the assumption made in azocasein's original protocol [6], which states that a completely digested azocasein solution has the same colour intensity as an undigested sample.

The calibration curve is obtained by plotting the optical density measured when the time of digestion was $420 \mathrm{~min}$ and the concentration of substrate at $t=0$.

2.7. Detection and Quantification Limits. The limit of detection (LoD) and limit of quantification (LoQ) for the protocol were based on the standard deviation of the response and the slope of the mean of calibration curves, following $\mathrm{ICH}^{*}$ 's guidelines [17], and are given by the equations below:

$$
\begin{aligned}
& \mathrm{LoD}=\frac{3.3 \cdot \sigma}{s}, \\
& \mathrm{LoQ}=\frac{10 \cdot \sigma}{s},
\end{aligned}
$$

where $\sigma$ is the standard deviation of the response and $s$ is the slope of the calibration curve. As described by ICH, the residual standard deviation of a regression line can be used as the standard deviation during calculations.

2.8. Stability Assays. Stability assays followed the protocols described in a document provided by the US Department of Health and Human Services called Guidance for Industry: Bioanalytical Method Validation [18].

Short-Term Temperature Stability. Three aliquots of each of the low and high concentrations were thawed at room temperature, kept for 8 hours, and then analysed.

Long-Term Stability. The storage time in a long-term stability was evaluated within an interval of six weeks, time usually necessary to perform a whole batch of our routine experiments. Long-term stability was determined by storing three aliquots of each of the low and high concentrations at $5^{\circ} \mathrm{C}$. To 


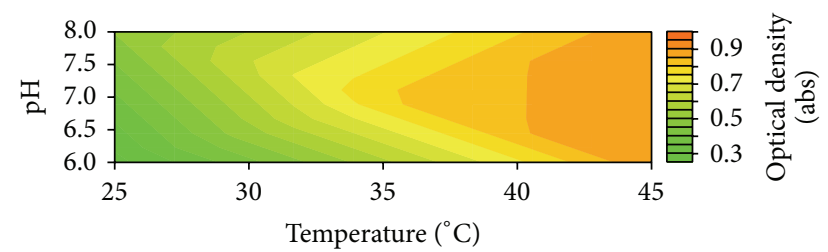

(a)

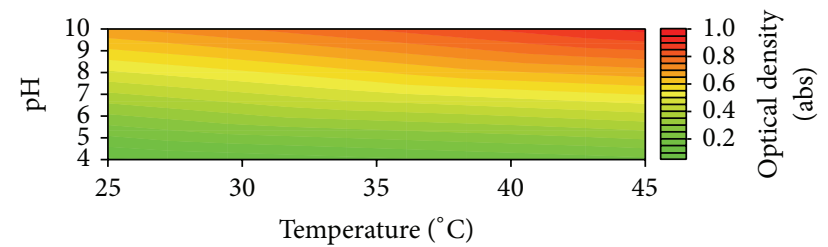

(b)

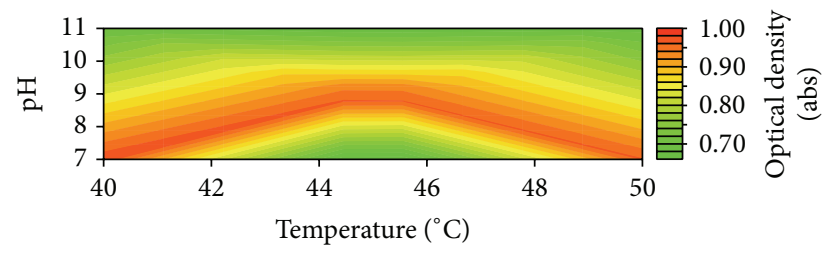

(c)

FIGURE 1: Response contour of conditions optimisation for bromelain solution.

avoid contamination, each sample was stored in its own vial and analysed on six separate occasions.

Freeze and Thaw Stability. Three aliquots at each of the low and high concentrations were stored at $-20^{\circ} \mathrm{C}$ for 24 hours and thawed unassisted at room temperature. When completely thawed, the samples were refrozen for 24 hours under the same conditions. The freeze-thaw cycle was repeated two more times and then analysed on the third cycle.

\section{Results and Discussion}

3.1. Optimum Conditions. The study and determination of bromelain's biochemical properties have been studied extensively before through several methods but our interest was to determine the optimum conditions specifically for the substrate under investigation to evaluate it at its best.

Figure 1(a) corresponds to results obtained from the first experimental design and shows that at such variable's range the $\mathrm{pH}$ seems to have no influence over the enzyme activity.

Then we modified the experimental design by increasing the $\mathrm{pH}$ 's range in order to confirm the observation. However, the enzyme showed some increase in its activity at basic $\mathrm{pH}$ (Figure 1(b)) and served to establish the variables range for the central composite design (CCD) shown in Table 1.

Figure 1(c) shows clearly that bromelain has an impressively wide range of $\mathrm{pH}$ and temperature that can digest azocasein substrate with no apparent loss in its sensitivity. It also shows that bromelain is still active at moderately high temperatures [19]. Due to local operational reasons we chose $\mathrm{pH} 9$ and $45^{\circ} \mathrm{C}$ as the conditions to be used in the next steps

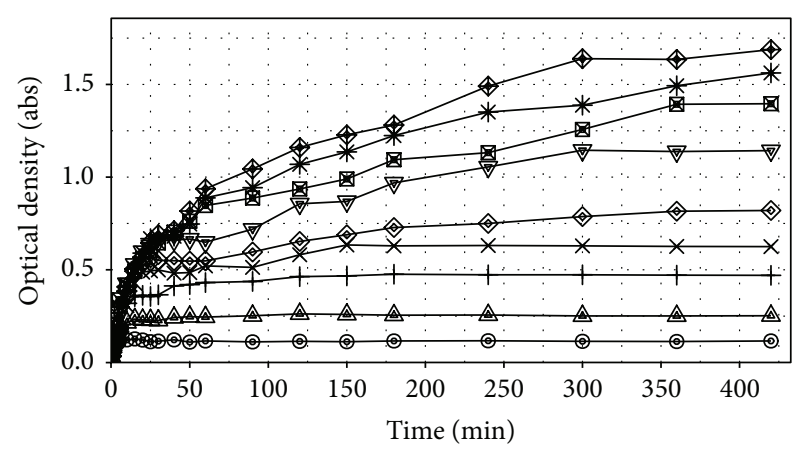

Azocasein concentration
$\begin{array}{ll}\odot 0.10 \% & \nabla 1.50 \% \\ \triangle 0.25 \% & \text { 田 } 2.00 \% \\ +0.50 \% & * 2.50 \% \\ \times 0.75 \% & \diamond 3.00 \% \\ \diamond 1.00 \% & \end{array}$

Figure 2: Azocasein digestion curve at $45^{\circ} \mathrm{C}$ and $\mathrm{pH} 9$ using bromelain $1 \mathrm{mg} / \mathrm{mL}$ with substrate concentration from 0.1 to $3 \%$ $(\mathrm{w} / \mathrm{w})$.

TABLE 1: Rotational central composite design used to study and determine assay's optimum conditions shown in Figure 1(c).

\begin{tabular}{cccc}
\hline & Factor & Temperature $\left({ }^{\circ} \mathrm{C}\right)$ & $\mathrm{pH}$ \\
\hline \multirow{4}{*}{ Levels } & -1.414 & 37.93 & 6.17 \\
& -1.000 & 40.00 & 7.00 \\
& 0.000 & 45.00 & 9.00 \\
& 1.000 & 50.00 & 11.00 \\
& 1.414 & 52.07 & 11.80 \\
\hline
\end{tabular}

of this study. For this case, pH 9 Glycine-NaOH (100 mM) buffer was used during substrate preparation.

3.2. Calibration Curve. Figure 2 shows the kinetics curves obtained for each concentration of azocasein substrate used. As expected, curves with lower substrate concentration were completely digested in a matter of a few minutes, while solution at $3 \%, 2.5 \%$, and $2 \%$ seems to be closer to such point but the enzymatic reaction would still be in process.

By plotting the azocasein concentration against its correspondent optical density for all curves at $420 \mathrm{~min}$ and using the assumption made by Charney and Tomarelli [6] we obtain a calibration curve which creates a relationship between these two variables (Figure 3 ).

The substrate concentration was converted easily from mass fraction to $\mathrm{mg} \cdot \mathrm{mL}^{-1}$ by taking in account the solvents specific mass and the volume retraction caused by the addition of ethanol.

The divergence between curves is mainly due the fact that reactions using substrate at $2.5 \%$ and $3.0 \%$ seem to have significant amounts of undigested substrate and thus the assumption becomes invalid. Therefore, the solid line (SL) curve represents the data series without these points. Results from statistical analysis for both curves are presented in Table 2. 
TABLE 2: Summary of statistical analysis results for both curves.

\begin{tabular}{lccccc}
\hline & & Coefficients & Std. error & $t$-value & $R^{2}$ \\
\hline \multirow{2}{*}{ Solid line (SL) } & Intercept & -0.13561 & 0.04493 & 3.018 & 26.673 \\
& Slope & 1.47572 & 0.05533 & 0.9916 \\
\hline \multirow{2}{*}{ Dashed line (DL) } & Intercept & -0.2700 & 0.1161 & 2.326 & 15.764 \\
& Slope & 1.7441 & 0.1106 & 0.9687 \\
\hline
\end{tabular}

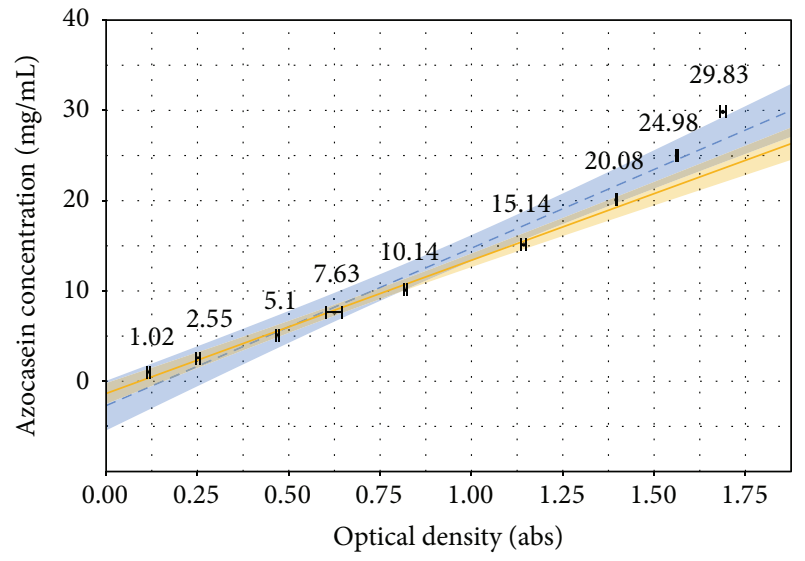

FIgURE 3: Calibration curves for azocasein concentration using 1 $20 \mathrm{mg} / \mathrm{mL}$ (solid line, SL) and 1 30 mg/mL (dashed line, DL).

As the presented data suggests, it is clear that removing the points related to unfinished reactions put the correlation in a confidence level allowing it to be used as a calibration curve. Consider

$$
C_{\mathrm{AZO}}(\mathrm{mg} / \mathrm{mL})=-0.13561+1.47572 \cdot \text { Abs. }
$$

The limits of detection and quantification were calculated using (1) and their results are presented below. Data was converted to $\mathrm{mg} \cdot \mathrm{mL}^{-1}$ using (2) and coefficients obtained for SL. Consider

$$
\begin{aligned}
\mathrm{LoD} & =\frac{3.3 \cdot \sigma}{s}=\frac{3.3 \cdot(0.06295)}{1.47572}=0.1407686 \mathrm{Abs} \\
& =0.072 \mathrm{mg} / \mathrm{mL} \\
\mathrm{LoQ} & =\frac{10 \cdot \sigma}{s}=\frac{10 \cdot(0.06295)}{1.47572}=0.4265714 \mathrm{Abs} \\
& =0.494 \mathrm{mg} / \mathrm{mL} .
\end{aligned}
$$

One unit (U) of proteolytic activity was defined as the amount of enzyme capable of digesting $1 \mathrm{mg}$ of substrate per minute, as given in the equation below:

$$
A_{(\mathrm{U})}=\frac{C_{\mathrm{AZO}} \cdot V_{\mathrm{Total}}^{2}}{t \cdot V_{\mathrm{ENZ}}},
$$

where $C_{\mathrm{AzO}}$ is the concentration of azocasein obtained using (2); $V_{\text {Total }}$ is the sum of volumes of TCA, substrate, and enzyme solution $\left(V_{\mathrm{ENZ}}\right)$ used in the digestion and $t$ is the digestion time (in minutes).

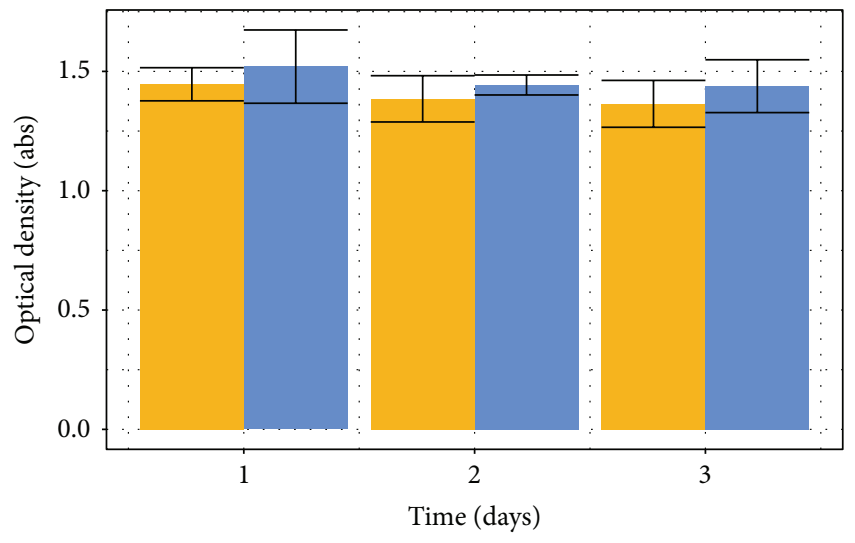

$$
\begin{aligned}
& \text { Azocasein concentration } \\
& 2.00 \% \\
& 3.00 \%
\end{aligned}
$$

FIGURE 4: Short-term stability results for azocasein substrate.

3.3. Stability Assays. Substrate's storage stability is another important feature to be evaluated in order to establish a protocol. Short-term stability is important to evaluate whether the substrate can be kept at room temperature during a daylong set of experiments (Figure 4).

Results of time $=0$ are relative to a substrate solution right after it was prepared, while subsequent days showed results of each sample, taken from the same stock solution, left for 8 hours at room temperature prior to analysis. Results show a significant loss of substrate response in both concentrations (around 10\%) when compared to the stock solution but that a similar variation is observed within the time interval studied.

Long-term stability is evaluated to check whether a solution can be stored and for how long, without been frozen.

While there was no observed formation of insoluble solids in the stock solution during storage, the response of substrate had a significant loss (around 17\%) after 14 days but then it stabilized (Figure 5). This fact does not seem to create any interference in any step of the method but suggests that the substrate solution would offer a maximum response when used right after preparation. Further studies will be necessary to understand the phenomena involved in the decrease of response over time.

The decrease in response for the substrate's digestion also occurred during freeze-thaw cycle (see Figure 6), which reinforces the hypothesis that it is not caused by microbial activity but somehow related to the substrate solubility. The observed errors were lower than the ones observed during 


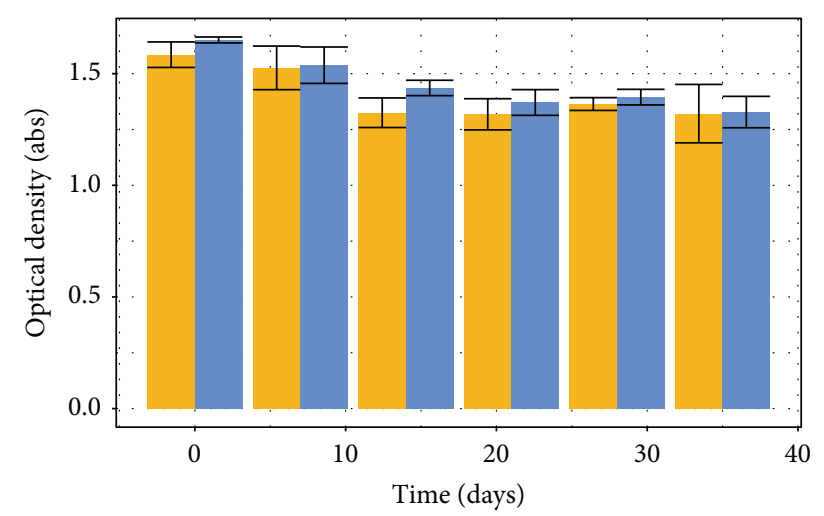

Azocasein concentration

- $2.00 \%$

- $3.00 \%$

FIGURE 5: Long-term stability for azocasein substrate stored at $5^{\circ} \mathrm{C}$.

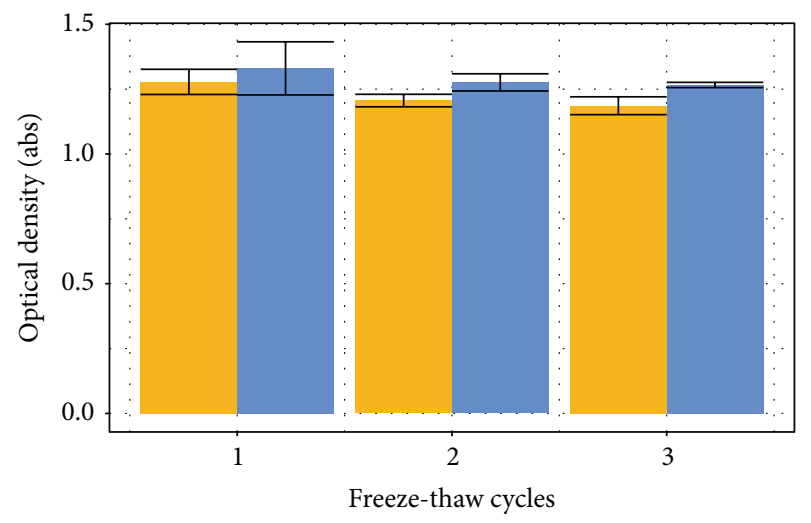

Azocasein concentration

$2.00 \%$

$3.00 \%$

FIGURE 6: Substrate stability after freeze-thaw cycles.

long-term and short-term studies, which make it the most suitable option for storage at the moment.

\section{Conclusion}

The protocol described followed the main guidelines presented by $\mathrm{ICH}^{*}$ and establishes a reliable procedure to analyse biological activity of proteolytic enzymes. Besides, the method uses a mass correlation between the substrate used and the optical density observed in the postdigestion sample. Although a simple and obvious idea, it offers a significant improvement, given that subjective definitions are commonly used in the literature. Besides, we ran a series of stability assays in order to evaluate the substrate and observed that a significant loss (10\%-20\%) occurred in all substrate samples, suggesting that substrate solution offers an enhanced response when prepared right after its use. As the understanding of the mechanism controlling the loss in substrate response was not part of this research, further experiments will be performed and analysed separately.

\section{Nomenclature}

ICH: International Conference on Harmonisation of Technical Requirements for Registration of Pharmaceuticals for Human Use.

\section{Conflict of Interests}

The authors declare that there is no conflict of interests regarding the publication of this paper.

\section{Acknowledgments}

The authors would like to acknowledge the financial support of FAPESP (São Paulo Research Foundation), PROPP-UFU (Dean of Research and Graduate Studies at the Federal University of Uberlândia), and CNPq (National Council for Scientific and Technological Development). This Project has been funded by grants from Sao Paulo Research Foundation: FAPESP 2011/20733-7 and FAPESP 2012/14533-8.

\section{References}

[1] O. P. Ward, "3.49-proteases," in Comprehensive Biotechnology, M.-Y. Murray, Ed., pp. 571-582, Academic Press, Burlington, Mass, USA, 2nd edition, 2011.

[2] H. R. Maurer, "Bromelain: biochemistry, pharmacology and medical use," Cellular and Molecular Life Sciences, vol. 58, no. 9, pp. 1234-1245, 2001.

[3] S. Cumming, Global Market for Industrial Enzymes to Reach Nearly \$7.1 Billion by 2018; Detergent Enzyme Market to Record Maximum Growth, BIO030H, PRWeb, 2014, http://www .bccresearch.com/market-research/biotechnology/enzymes-industrial-applications-bio030h.html.

[4] J. R. Cherry and A. L. Fidantsef, "Directed evolution of industrial enzymes: an update," Current Opinion in Biotechnology, vol. 14, no. 4, pp. 438-443, 2003.

[5] M. Mccoy, "Novozymes emerges," Chemical \& Engineering News, vol. 79, no. 8, pp. 23-25, 2001.

[6] J. Charney and R. M. Tomarelli, "A colorimetric method for the determination of the proteolytic activity of duodenal juice," The Journal of Biological Chemistry, vol. 171, no. 2, pp. 501-505, 1947.

[7] N. S. Leite, A. A. B. de Lima, J. C. C. Santana et al., "Determination of optimal condition to obtain the bromelain from pineapple plants produced by micropropagation," Brazilian Archives of Biology and Technology, vol. 55, no. 5, pp. 647-652, 2012.

[8] L. F. Domingues, R. Giglioti, K. A. Feitosa et al., "In vitro and in vivo evaluation of the activity of pineapple (Ananas comosus) on Haemonchus contortus in Santa Inês sheep," Veterinary Parasitology, vol. 197, no. 1-2, pp. 263-270, 2013.

[9] C. Mohan, Buffers: A Guide for the Preparation and Use of Buffers in Biological Systems, Calbiochem-Behring Corporation, La Jolla, Calif, USA, 2008.

[10] L. P. Hale, P. K. Greer, C. T. Trinh, and C. L. James, "Proteinase activity and stability of natural bromelain preparations," International Immunopharmacology, vol. 5, no. 4, pp. 783-793, 2005.

[11] R Core Team, R: A Language and Environment for Statistical Computing, R Foundation for Statistical Computing, Vienna, Austria, 2015. 
[12] RStudio Inc, RStudio: Integrated Development Environment (IDE) for R, vol. 0.98.1103, RStudio Inc, Boston, Mass, USA, 2015.

[13] A. Gebhardt, H. Akima, and T. Petzoldt, Akima: Interpolation of Irregularly Spaced Data, R Package Version 0.5-11, 2013.

[14] U. Groemping, DoE.base: Full Factorials, Orthogonal Arrays and Base Utilities for DoE Packages, R Package Version 0.27, 2015.

[15] H. Wickham, ggplot2: Elegant Graphics for Data Analysis, Springer, New York, NY, USA, 2009.

[16] E. Neuwirth, $R$ Color Brewer: Color Brewer Palettes, R Package Version 1.1-2, 2014.

[17] ICH Expert Working Group, Validation of Analytical Procedures: Text and Methodology Q2 (R1), ICHHT-ICH Harmonised Tripartite Guideline, 2005.

[18] Food and Drug Administration, Draft Guidance for Industry: Bioanalytical Method Validation, US Food and Drug Administration, Rockville, Md, USA, 1999.

[19] B. C. Martins, R. Rescolino, D. F. Coelho, B. Zanchetta, E. B. Tambourgi, and E. Silveira, "Characterization of bromelain from ananas comosus agroindustrial residues purified by ethanol factional precipitation," Chemical Engineering Transactions, vol. 37, pp. 781-786, 2014. 

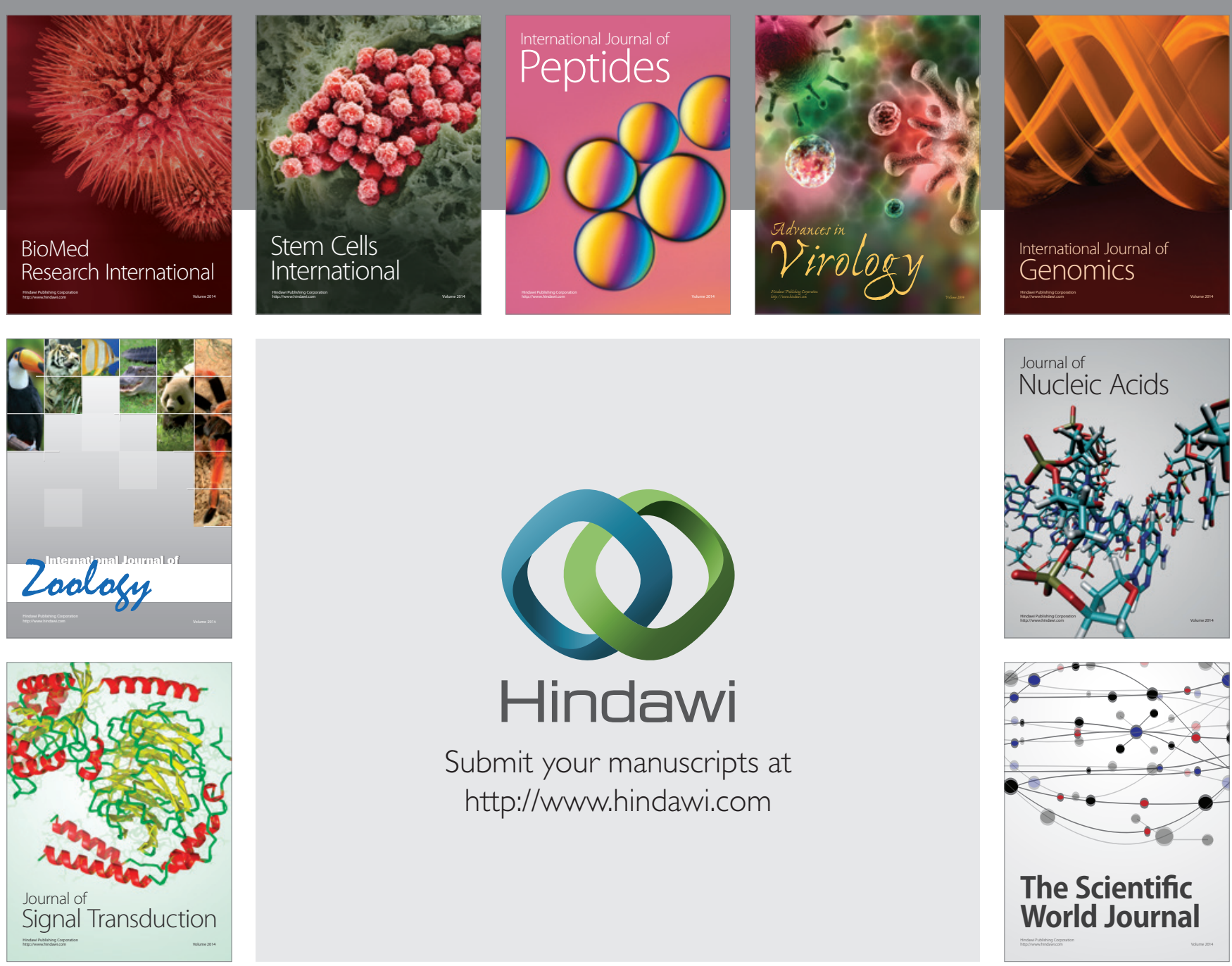

Submit your manuscripts at

http://www.hindawi.com
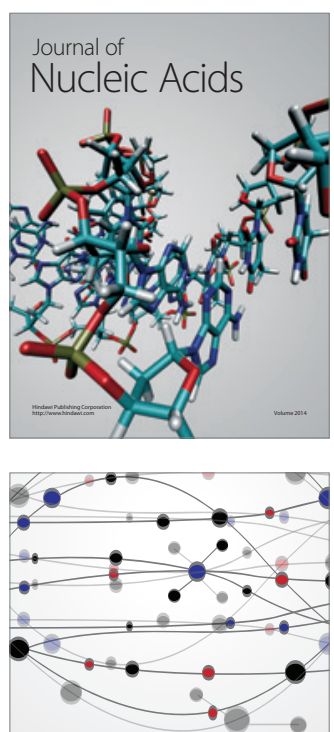

The Scientific World Journal
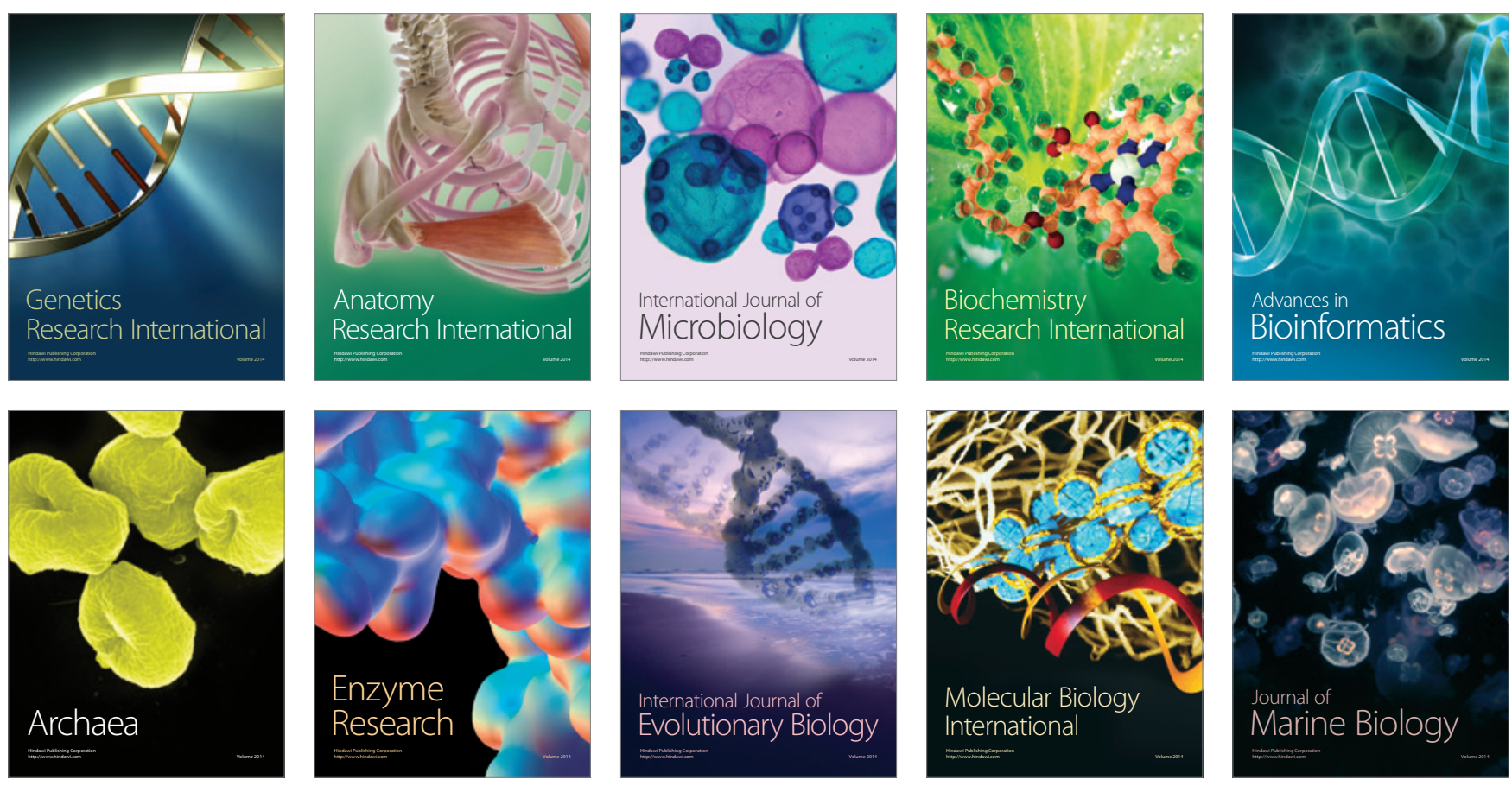